\title{
User Engagement and Clinical Impact of the Manage My Pain App in Patients With Chronic Pain: A Real-World, Multi-site Trial
}

Anuj Bhatia ${ }^{1,2}$, MD, FRCPC; Jamal Kara ${ }^{3,4}$, BSc, CCRP; Tahir Janmohamed ${ }^{5}$, BSc, MBA; Atul Prabhu ${ }^{1}$, MBBS, FRCPC; Gerald Lebovic ${ }^{2,6}$, BSc, MSc, PhD; Joel Katz ${ }^{1,7}$, MA, PhD; Hance Clarke ${ }^{1,8}$, MD, PhD, FRCPC

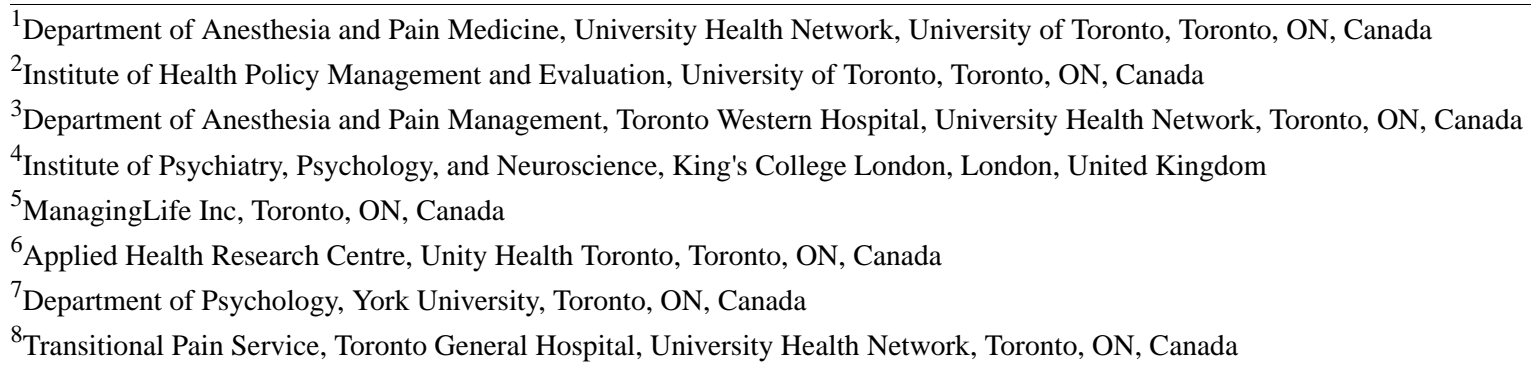

\section{Corresponding Author:}

Anuj Bhatia, MD, FRCPC

Department of Anesthesia and Pain Medicine

University Health Network

University of Toronto

McL 2-405

399 Bathurst Street

Toronto, ON, M5T 2S8

Canada

Phone: 14166035800 ext 6136

Email: anuj.bhatia@uhn.ca

\section{Abstract}

Background: Chronic pain imposes a large burden on individuals and society. A patient-centric digital chronic pain management app called Manage My Pain (MMP) can be used to enhance communication between providers and patients and promote self-management.

Objective: The purpose of this study was to evaluate the real-world engagement of patients in urban and rural settings in Ontario, Canada with the MMP app alongside their standard of care and assess the impact of its usage on clinical outcomes of pain and related mental health.

Methods: A total of 246 participants with chronic pain at a rural and 2 urban pain clinics were recruited into this prospective, open-label, exploratory study that compared the use of MMP, a digital health app for pain that incorporates validated questionnaires and provides patients with summarized reports of their progress in combination with standard care (app group), against data entered on paper-based questionnaires (nonapp group). Participants completed validated questionnaires on anxiety, depression, pain catastrophizing, satisfaction, and daily opioid consumption up to 4.5 months after the initial visit (short-term follow-up) and between 4.5 and 7 months after the initial visit (long-term follow-up). Engagement and clinical outcomes were compared between participants in the two groups.

Results: A total of 73.6\% (181/246) of the participants agreed to use the app, with 63.4\% (111/175) of them using it for at least one month. Individuals who used the app rated lower anxiety (reduction in Generalized Anxiety Disorder 7-item questionnaire score by 2.10 points, $95 \% \mathrm{CI}-3.96$ to -0.24 ) at short-term follow-up and had a greater reduction in pain catastrophizing (reduction in Pain Catastrophizing Scale score by 5.23 points, $95 \%$ CI -9.55 to -0.91) at long-term follow-up relative to patients with pain who did not engage with the MMP app.

Conclusions: The use of MMP by patients with chronic pain is associated with engagement and improvements in self-reported anxiety and pain catastrophizing. Further research is required to understand factors that impact continued engagement and clinical outcomes in patients with chronic pain.

Trial Registration: ClinicalTrials.gov NCT04762329; https://clinicaltrials.gov/ct2/show/NCT04762329 
(JMIR Mhealth Uhealth 2021;9(3):e26528) doi: 10.2196/26528

\section{KEYWORDS}

pain; psychology; patient-oriented research; quality of life; digital health; chronic pain; pain app; virtual care; mHealth; pain management; chronic disease management; remote monitoring; app; engagement; impact; outcome

\section{Introduction}

Several large population-based surveys show that over 1 in 5 people live with chronic pain [1-5]. Pain is associated with poor quality of life [6] and is one of the top 3 reasons to seek medical attention in Canada [7,8]. The combined direct and indirect annual costs of chronic pain in North America are estimated to be more than US $\$ 650$ billion [6,9-11]. Despite these staggering numbers, there are barriers to improving the management and outcomes of chronic pain, including obtaining longitudinal data, assessing response to interventions, and addressing challenges to communication between patients and health care providers (HCPs) [12]. The need to maintain continuity of care for chronic pain patients has also become imperative to avoid treatment disruptions due to public health emergencies, such as COVID-19, limiting in-person visits $[13,14]$.

To bridge this gap, a patient-centric digital health app can be used as a method of remote monitoring to enhance communication between patients and HCPs and promote self-management of patients' symptoms. While a number of pain apps have been created, they evaluate the biopsychosocial components of pain experiences inadequately and lack clinical involvement [12,15-17]. The scientific validation process for these digital pain apps has not focused on development, adoption, engagement, and patient satisfaction [18-21]. None have been scientifically validated for their impact on pain-related clinical outcomes $[16,17]$. The few digital pain management solutions that have been scientifically validated for positive clinical impact are specific to patients with lower back pain rather than focused on generalized chronic pain, which is prevalent in a multitude of patients with underlying medical conditions [22]. Furthermore, most studies do not address the effectiveness of mobile pain apps based on clinical setting, despite major lifestyle differences of individuals who live in urban and rural areas [23]. Mobile health apps also have difficulty engaging patients, with top-performing health apps having an average 30-day retention rate of only $15 \%$ [24].

A novel digital pain management solution, the Manage My Pain (MMP) app (ManagingLife Inc) [25], was used in this study by patients and HCPs to measure and monitor pain, mental health, and medication use. The purpose of this study was to evaluate the real-world engagement of patients in urban and rural settings in Ontario, Canada with the MMP app alongside their standard of care. Engagement was ascertained by evaluating both adoption and retention rates for continuing use of this app over time. Clinical outcomes of pain and related mental health were also measured and compared between patients who engaged with the app versus those who proceeded with the standard of care at their respective institutions.

\section{Methods}

\section{Study Sites and Participants}

A prospective, open-label, multicenter exploratory study with active and comparator arms was conducted from January 8, 2018, to January 7, 2020, at 3 study sites. Participants were recruited from among new patients with chronic pain conditions who were referred to 2 tertiary academic pain centers in Toronto, Ontario, Canada (Toronto General Hospital [TGH] and Toronto Western Hospital [TWH]) and a rural pain clinic in Ontario (the Iroquois Falls Family Health Team [IFFHT] pain clinic in Iroquois Falls, Ontario). All patients had pain of moderate-to-severe intensity that had persisted for at least three months. All patients, regardless of use of the Manage My Pain app, received the standard of care for the particular clinic, which included interventions such as medication management, psychological therapy, and physiotherapy.

\section{The Manage My Pain Digital Health Solution}

Manage My Pain [26], the app used for this study, is a digital health solution that comprises 3 components: (1) an app for patients to track their pain, function, and medication; respond to questionnaires; and view insights on their conditions; (2) reports that summarize the information collected in the app to be used during clinical visits to facilitate communication between patients and clinicians; and (3) a monitoring portal used by clinics to remotely assess patient progress, assign questionnaires, and highlight clinically relevant trends and patterns using advanced analytics [25]. MMP was first launched in 2011 as the first pain management app on the Android platform. In 2015, ManagingLife partnered with the multidisciplinary team to evolve the solution to meet clinical needs and successfully integrate it into the clinical workflow of an outpatient clinic of an academic hospital [27]. Several papers have applied machine learning techniques to analyze the engagement patterns of users within MMP and develop prediction models from its data set of over 50,000 users [28-30].

MMP is used by both patients and clinics to measure and monitor pain, function, and medication use. Patients can record their experiences by using the MMP app on their mobile device (compatible with Android and iOS devices) or accessing a web-based platform. When prompted by an in-app push notification triggered at 8 PM daily, patients record daily reflections in the app, where they indicate the meaningful activities they were able to accomplish. The daily reflection concept is based on acceptance and commitment therapy principles that have demonstrated an ability to improve clinical outcomes relevant to pain management [27]. Patients also record their pain episodes, including descriptions such as severity, locations, associated symptoms, characteristics, duration, environment, and aggravating or alleviating factors (Figure 1). 
Figure 1. Screenshots of the screens used by Manage My Pain to collect patient-reported outcomes.

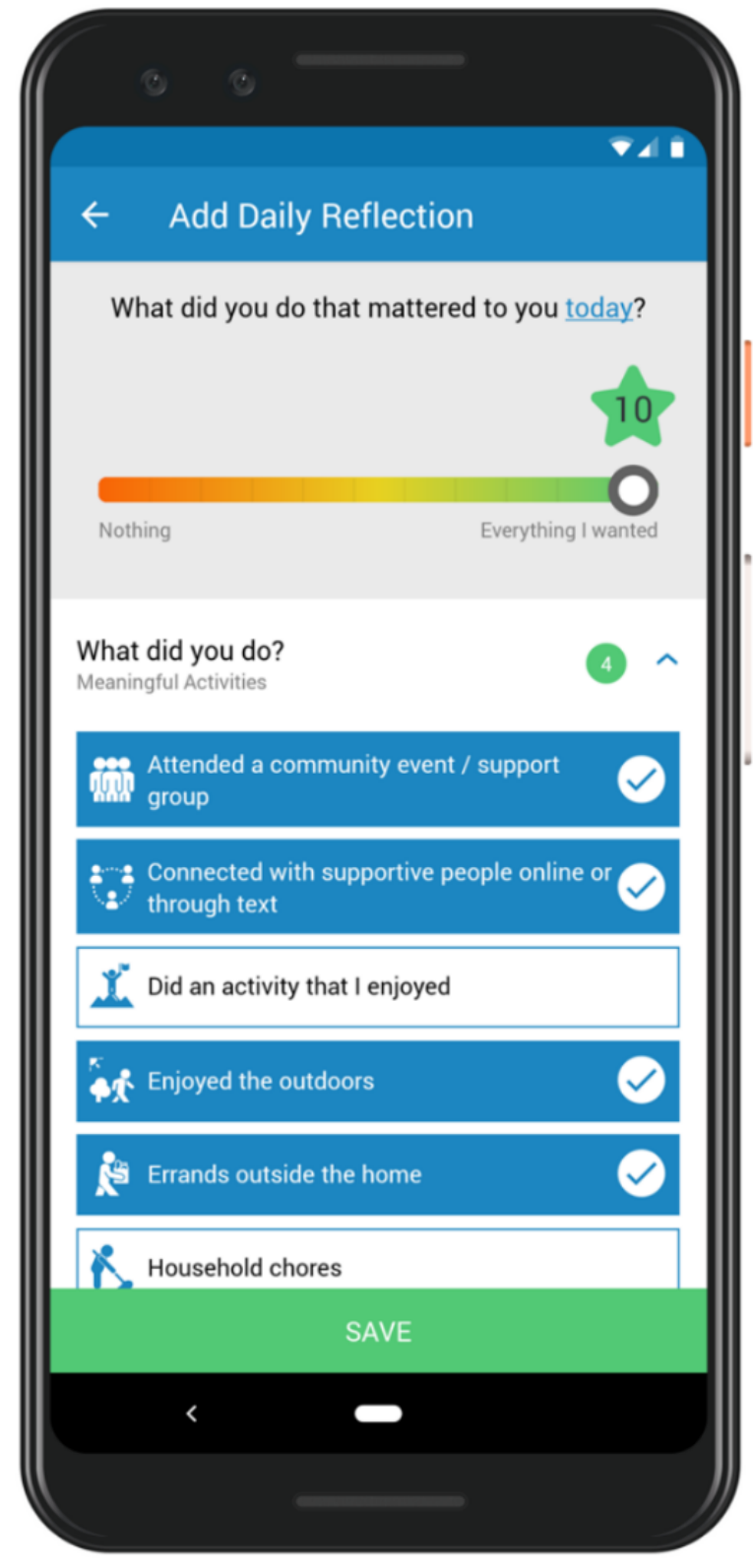

Each section of the app can be customized by the patient so that it is representative of their situation. MMP is designed to capture both daily reflections and pain episodes in less than 60 seconds [25]. As patients enter information into the app, charts and graphs are presented to the patient to highlight patterns and trends that increase self-awareness of their condition and provide insight into triggers and interventions. With consent, this information can also be viewed by their clinical team through MMP's remote monitoring portal. For clinics, pain and function trends are summarized across a predefined time period and can be viewed digitally or output into a clinician-friendly concise report. These self-reported outcomes are used to improve

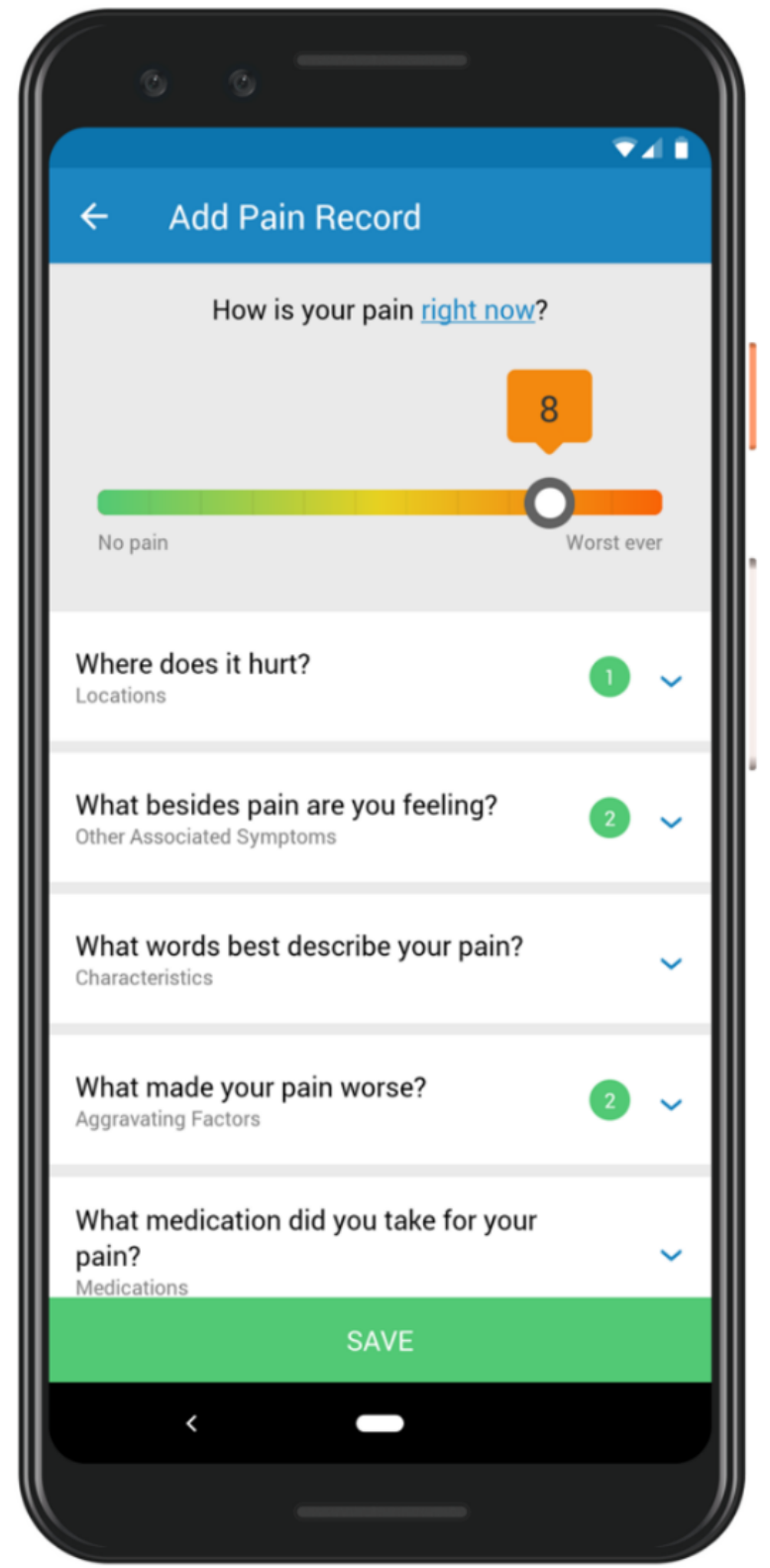

communication with a patient during a clinical visit and assess progress more objectively between clinical visits. Moreover, MMP allows clinics to assign validated questionnaires on pain and related domains for patients to complete at home in advance of their clinical visit. Responses to these questionnaires, along with their corresponding scores and interpretations, are also available through the MMP portal and can be summarized in the clinician-facing report (Figure 2). Emails are sent to the patients by MMP at predefined intervals to encourage engagement with the app and prompt patients to complete the questionnaires by the specified due date. 
Figure 2. Sample clinician-facing report produced by Manage My Pain that contains scored responses to validated measures as well as a summary of the daily tracking.

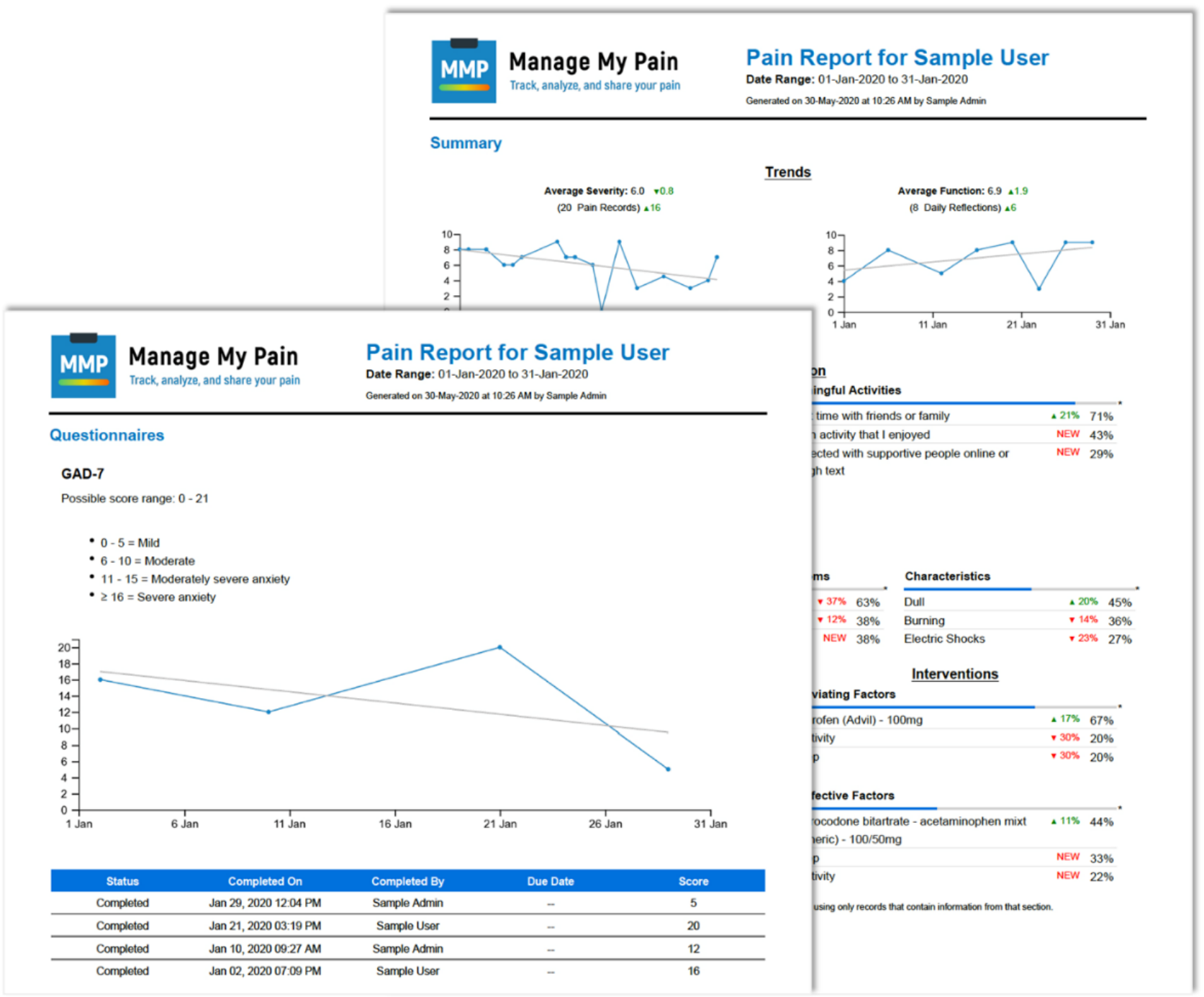

\section{Recruitment}

As part of the registration process, patients were shown a consent screen asking for permission to share the information from MMP with their clinical team for clinical and research purposes, and they signed an informed consent form. Participants had to explicitly agree by entering a unique randomized 10-digit ID provided to them by the research coordinator, which allowed each clinic to match the participant with their clinical profile and ensure appropriate deidentification. After registration, participants had to activate their account by clicking on a link sent to them by email. Participants were instructed to download MMP through either the Apple App Store (for iPhone users) or the Google Play Store (for Android users) upon successful activation. For participants that did not have either device, a web link associated with their clinic was bookmarked for them to use MMP through their internet browser for easy access.

At first access, the app provided a brief tutorial on how to set up the user's profile, which included entering relevant medications and pain conditions. It then described how to complete a sample entry by using a touch slider to enter a numerical rating score as an integer from 0 to 10 . Once the user's pain level was indicated, additional questions were prompted, including pain location, other associated symptoms, pain characteristics, aggravating and alleviating factors, and the duration and environment of the pain episode. While all questions included a drop-down menu including prepopulated answers with associated infographics, participants were also given the option to add customized values. A Notes section where participants could enter free text was also provided. Upon completion, patients could save their entry for the patient and health care team to track and observe trends. Technical support was also offered to the participants in the event that they required troubleshooting for using the app, either by the designated research team or the ManagingLife technical support team. Email notifications for data entry on validated questionnaires were sent by the app 7 days prior to the due date set by the research coordinator, which was intended to coincide with the date of the clinical visit. This feature allowed HCPs to track the progress of patients who could not be seen through in-person visits.

\section{Study Procedures}

Participants at the 3 sites were selected using a homogeneous purposive sampling method [31] and given an option to use the 
app. During the first clinical visit, patients who consented to the study for their data to be collected were offered a choice to either register an account with the app [25] to share their data with the research and clinical teams through the app's monitoring portal or provide their data on paper-based questionnaires during pain clinic visits. Participants who continued to record their pain experiences and enter data in the app after 30 days of first registering were considered to be in the app group. Participants who declined to use the app or those who registered but had no records in the app after 30 days were considered to be in the nonapp group. A cutoff of 30 days was used based on its acceptance in the mobile app industry as a benchmarked metric of retention [24] and on its determination by the clinical team involved in the study as a meaningful duration of information that could inform clinical decision making.

Participants were asked to complete questionnaires on the following pain-related outcomes: anxiety, depression, pain catastrophizing, pain disability, patient global impression of change, and daily opioid consumption. Daily opioid consumption was measured in oral morphine equivalents in milligrams upon entry into the study during the initial visit and as a part of the first follow-up clinical visit within 4.5 months of the initial visit (short-term follow-up) and during the second follow-up clinical visit between 4.5 and 7 months after the initial visit (long-term follow-up). Given that our objective was to validate the impact of the app in a real-world clinical environment, the date ranges of follow-up visits were more broadly defined to align with the date of the actual clinical visit. Clinicians at each participating site were encouraged to use the clinical reports, either digitally through the portal or printed, during their clinical visits with the patients.

Participants who agreed to use the app but did not have in-person clinical appointments within these time frames were still remotely prompted to complete the questionnaires through the app portal by research staff. Patients in the nonapp group provided their data only by completing paper-based questionnaires during clinic visits or via a phone interview if no in-person clinical visit was scheduled during study-related follow-ups.

\section{Validated Measures Used in the Study}

The feasibility and successful adoption of the digital health solution was evaluated through clinical outcomes and patient engagement. During the initial visit, participants completed baseline questionnaires that were standardized across sites as well as questionnaires that were considered the standard of care at each individual clinical practice.

As mood disorders are often prevalent in individuals with chronic pain and have been known to affect and intensify pain perception [32,33], anxiety and depression levels were recorded using the Generalized Anxiety Disorder 7-item questionnaire (GAD-7) and the Patient Health Questionnaire 9-item scale (PHQ-9) for depression, respectively. These questionnaires have repeatedly demonstrated excellent test-retest reliability [34], criterion and construct validity [35], and high levels of specificity and sensitivity in the assessment of anxiety and depression in patients with chronic pain [34-38]. In addition, the score on the Pain Disability Index (PDI), a 7-item instrument used to evaluate the degree of pain-related disability, can be inversely correlated with overall function [39]. The Pain Catastrophizing Scale (PCS) was also administered to participants to measure the degree of maladaptive cognitive distortions known as catastrophizing, which increase negative emotional schema throughout the anticipation and experience of painful stimulation [40,41]. Additionally, the Patient Global Impression of Change (PGIC) questionnaire, a 7-level ordinal measure, was administered to participants at both short-term and long-term follow-up time frames to assess the degree of improvement or worsening of a patient's clinical condition. The PGIC is a single-item validated questionnaire that asks the user about their perceived improvement and is significantly correlated with changes in pain intensity, efficacy of treatment, and interference of pain in daily activities [42].

Finally, participants' opioid consumption was measured over time using oral morphine equivalents (OME) through conversion ratios outlined by the Canadian Guideline for Safe and Effective Use of Opioids for Chronic Non-Cancer Pain [43]. Given that the core functionality of Manage My Pain is to record pain intensity scores during each engagement with the app, it was not selected as a measure for evaluation, as any comparisons against patients recording this information using point-in-time questionnaires would be misleading. Specifically, other measures were selected to assess the mental and physical well-being of patients independent of their severity and intensity.

\section{Ethics Approval}

Institutional ethics board approvals were obtained from each study site by the University Health Network Research Ethics Board for the academic sites (TGH and TWH) and Veritas Institutional Review Board for the rural site (IFFHT). The approval process involved confirmation that MMP has the administrative and technical safeguards in place to ensure compliance with privacy legislation.

\section{Statistical Analyses}

Continuous data were summarized using mean and standard deviation or median and interquartile ranges, and categorical data were summarized using frequency and percentages. Univariate tests for continuous data were conducted using 2-sample $t$ tests or Wilcoxon rank sum tests as appropriate based on the distribution of the data. Chi-square tests or Fisher exact tests were used for categorical data. A random-effects model was used for all outcomes to account for correlations arising from repeated measures within the same individual.

The main exposure of interest was whether someone used the app for at least 30 days, adjusted for time, age, gender, and study site. Each of the 6 outcomes (daily OME, GAD-7 score, PHQ-9 score, PDI score, PCS score, and PGIC score) was also modeled to examine the association of the intervention (use of the app for at least 30 days) with the outcome after controlling for other relevant variables. The duration of usage (time) among the participants who entered data into the app was recorded as the difference between the most recent entry and the date of registration. An interaction term between time (short term or long term) and group (intervention or control) was examined 
to determine whether the intervention was associated with differences between groups over time. A likelihood ratio test was used to assess the statistical significance of the interaction term, and the term was included in the model if it remained statistically significant at the .05 significance level. For clinical utility, the primary analysis categorized time as baseline, short term, and long term. A sensitivity analysis was conducted using time as a continuous covariate of interest. The baseline value was adjusted for by including it in the outcome vector [44]. Model checking for continuous outcomes was performed using analysis of residuals. Bootstrapped $95 \%$ confidence intervals and $P$ values were provided where the model residuals violated the normality assumption.

\section{Results}

\section{Data at Baseline and Engagement With the App}

The average age of participants in the study was 56.67 (SD 13.12) years, with $60.2 \%$ (148/246) of participants being female.
A total of 246 participants were enrolled across the 3 sites (154 participants at the 2 urban sites and 92 participants at the rural site), out of which $181(73.6 \%)$ accepted the use of the app in their clinical care and the remaining $65(26.4 \%)$ continued with paper-based data entry at their respective clinics. Of the 181 participants who agreed to use the app, $175(96.7 \%)$ participants registered and provided consent to share their data. Of the 175 participants who registered, $111(63.4 \%)$ participants used the app for at least 30 days and therefore were considered part of the intervention (app) group (Figure 3). Data from 70 participants who initially accepted the use of the app but either did not use the app or used it for less than 30 days were combined with data from the 65 participants who had declined to use the app at the start of the study, and these 135 participants were considered to be in the nonapp group for analysis (Figure $3)$. There were no differences between the app and nonapp groups with respect to demographics, duration of pain, or the validated measures for mood and physical disability (Table 1).

Figure 3. Flow diagram of group allocation based on participants' engagement with the app.

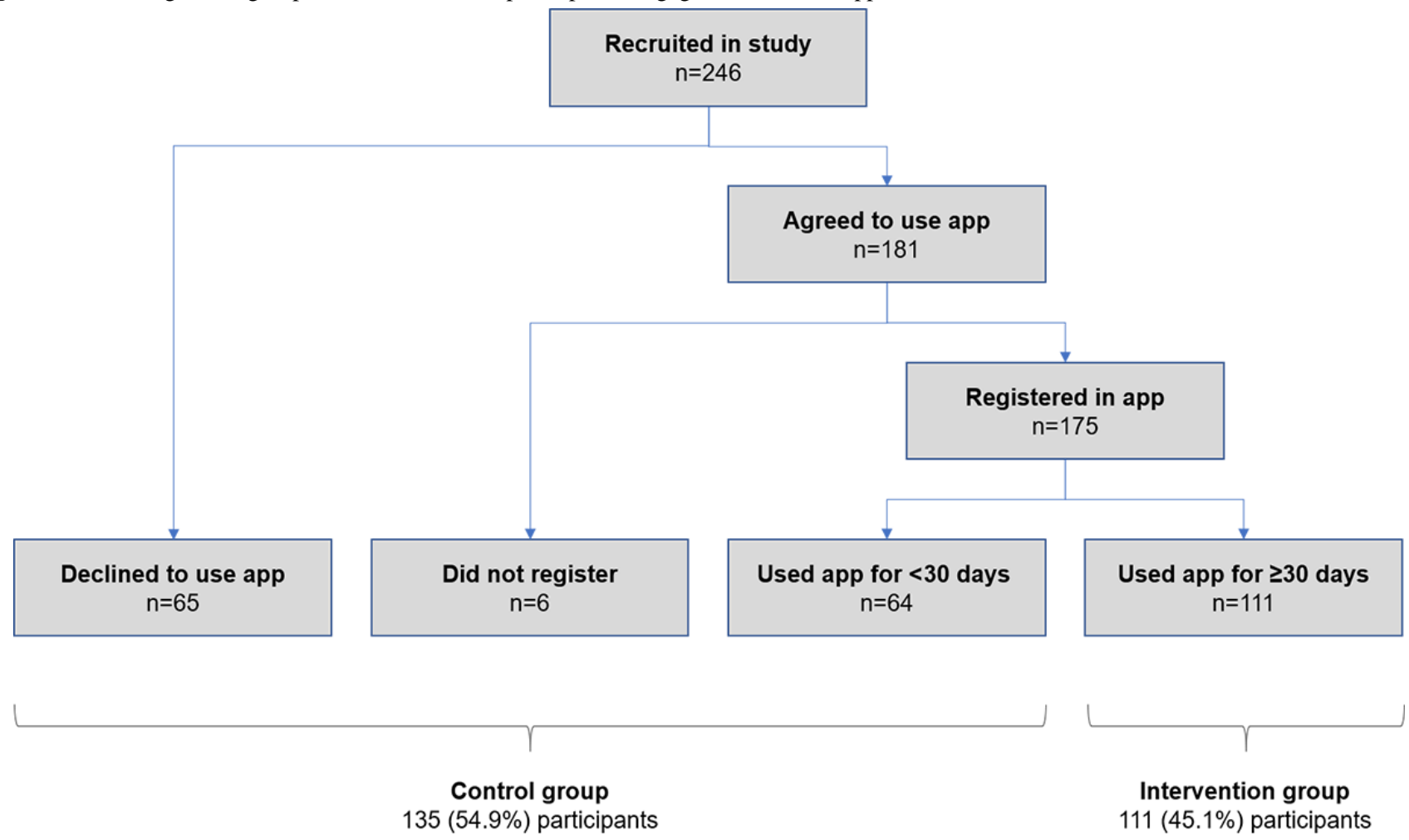


Table 1. Baseline demographics characteristics of the study population.

\begin{tabular}{|c|c|c|c|}
\hline Characteristic & $\begin{array}{l}\text { Nonapp group } \\
(\mathrm{n}=135)\end{array}$ & $\begin{array}{l}\text { App group } \\
(\mathrm{n}=111)\end{array}$ & $P$ value \\
\hline Age (years), mean (SD) & $57.17(15.07)$ & $56.05(10.31)$ & .51 \\
\hline Male sex, n (\%) & $59(44.0)$ & $39(35.1)$ & .20 \\
\hline Employment status, n (\%) & & & .69 \\
\hline Never worked & $1(0.8)$ & $0(0.0)$ & \\
\hline Not working & $58(45.3)$ & $51(46.4)$ & \\
\hline Working (part- or full-time) & $27(21.1)$ & $27(24.5)$ & \\
\hline Retired & $42(32.8)$ & $32(29.1)$ & \\
\hline Duration of pain, $n(\%)$ & & & .16 \\
\hline$<12$ months & $7(5.3)$ & $13(11.9)$ & \\
\hline 12-24 months & $13(9.8)$ & $12(11.0)$ & \\
\hline$>24$ months & $112(84.8)$ & $84(77.1)$ & \\
\hline Etiology of pain, $n(\%)$ & & & .005 \\
\hline Accident & $35(26.9)$ & $35(31.8)$ & \\
\hline As a result of illness & $27(20.8)$ & $11(10.0)$ & \\
\hline Following surgery & $13(10.0)$ & $8(7.3)$ & \\
\hline No known reason & $43(33.1)$ & $54(49.1)$ & \\
\hline Other & $12(9.2)$ & $2(1.8)$ & \\
\hline GAD-7 $7^{\mathrm{b}}$ score, mean $(\mathrm{SD})$ & $8.51(6.21)$ & $8.21(6.35)$ & .71 \\
\hline PHQ-9 ${ }^{\mathrm{c}}$ score, mean (SD) & $11.26(6.83)$ & $11.52(6.66)$ & .77 \\
\hline $\mathrm{PDI}^{\mathrm{d}}$ score, mean $(\mathrm{SD})$ & $40.30(16.47)$ & $41.76(15.11)$ & .49 \\
\hline $\mathrm{PCS}^{\mathrm{e}}$ score, mean (SD) & $23.84(13.19)$ & $24.93(14.39)$ & .55 \\
\hline $\mathrm{OME}^{\mathrm{f}}(\mathrm{mg} / 24 \mathrm{hr})$, median (IQR) & $0(0-30)$ & $0(0-27)$ & .42 \\
\hline
\end{tabular}

${ }^{\text {a }}$ The nonapp group included data from the 65 participants who had declined to use the app at the start of the study and the 70 participants who initially accepted use of the app but either did not use the app or used it for less than 30 days.

${ }^{\mathrm{b}}$ GAD-7: Generalized Anxiety Disorder 7-item scale.

${ }^{\mathrm{c}}$ PHQ-9: Patient Health Questionnaire 9-item scale.

${ }^{\mathrm{d}}$ PDI: Pain Disability Index.

${ }^{\mathrm{e}} \mathrm{PCS}$ : Pain Catastrophizing Scale.

${ }^{f}$ OME: oral morphine equivalents.

Of those who used the app for at least 30 days, the mean number of records entered was 113.4 (SD 129.7). The mean duration of usage from the date of registration to the date of the last record entered was 164.2 (SD 88.4) days.

\section{Clinical Outcomes}

Quantitative analysis of the clinical outcomes was performed at 2 time points, short term and long term, following enrollment into the study. Of the 135 patients in the nonapp group, 36 (26.7\%) provided their data at the short-term follow-up and 31 (23.0\%) provided their data at the long-term follow-up. A total of 90 of the 111 participants in the app group provided their data through the app for the short-term follow-up, and 69 provided their data for both short- and long-term follow-ups (Table 2). The primary reason for the large number of patients whose data were not available at the short-term follow-up is that many were deemed not to qualify for treatments offered at the clinics shortly after consenting to participate in the study and therefore were discharged from the clinic. The patients were discharged because these clinics accepted only patients with pain whose condition was amenable to the interventions offered at the clinic (eg, high-dose intravenous ketamine infusions, neuromodulation implants). For each of the measures collected from participants at the short-term and long-term follow-ups, less than $5 \%$ of data were missing for each time point, and no imputation technique was used.

The number of elapsed days from baseline for both the short-term and long-term follow-ups was not significantly different across the intervention and control groups (Table 3). 
Unadjusted analyses did not find any significant differences 4 and Figure 4). between the intervention and control groups over time (Table

Table 2. Number of participants with questionnaire responses at the short-term follow-up (prior to 4.5 months from baseline) and the long-term follow-up (between 4.5 and 7 months from baseline).

\begin{tabular}{lllll}
\hline Group & Participants, $\mathrm{n}$ & Baseline, $\mathrm{n}(\%)$ & Short-term, $\mathrm{n}(\%)$ & Long-term, $\mathrm{n}(\%)$ \\
\hline Nonapp & 135 & $130(96.3)$ & $36(27.7)$ & $31(23.8)$ \\
$\quad$ Declined to use app & 65 & $64(98.5)$ & $22(34.4)$ & $19(29.7)$ \\
$\quad$ Did not register & 6 & $3(50.0)$ & $2(66.7)$ & $2(66.7)$ \\
$\quad$ Used app for $<30$ days & 64 & $63(98.4)$ & $12(19.0)$ & $10(15.9)$ \\
App (used app for $\geq 30$ days) & 111 & $111(100.0)$ & $90(81.1)$ & $69(62.2)$ \\
Total & 246 & $241(98.0)$ & $126(52.3)$ & $100(41.5)$ \\
\hline
\end{tabular}

Table 3. Days from baseline for both short-term and long-term follow-up time periods. $P$ values used a Wilcoxon test and $95 \%$ CIs were bootstrapped.

\begin{tabular}{lllll}
\hline Time & $\begin{array}{l}\text { App group, median }(\mathrm{IQR}) \\
(\mathrm{n}=111)\end{array}$ & $\begin{array}{l}\text { Nonapp group, median (IQR) } \\
(\mathrm{n}=135)\end{array}$ & Difference (95\% CI) & $P$ value \\
\hline Short-term & $92(80-100)$ & $91(78-104)$ & $1(-7$ to 8$)$ & .80 \\
Long-term & $183(162-197)$ & $188.5(168-194)$ & $-5.5(-18$ to 2$)$ & .83 \\
\hline
\end{tabular}


Figure 4. Mean values of validated measures in both app (labelled "Intervention - Yes") and nonapp (labelled "Intervention - No") groups at short-term (early) and long-term (late) follow-ups. Error bars indicate the standard error. Means have been centered along the overall mean. GAD-7: Generalized Anxiety Disorder 7-item scale; OME: oral morphine equivalence; PCS: Pain Catastrophizing Scale; PDI: Pain Disability Index; PGIC: Participant Global Impression of Change; PHQ-9: Patient Health Questionnaire 9-item scale.

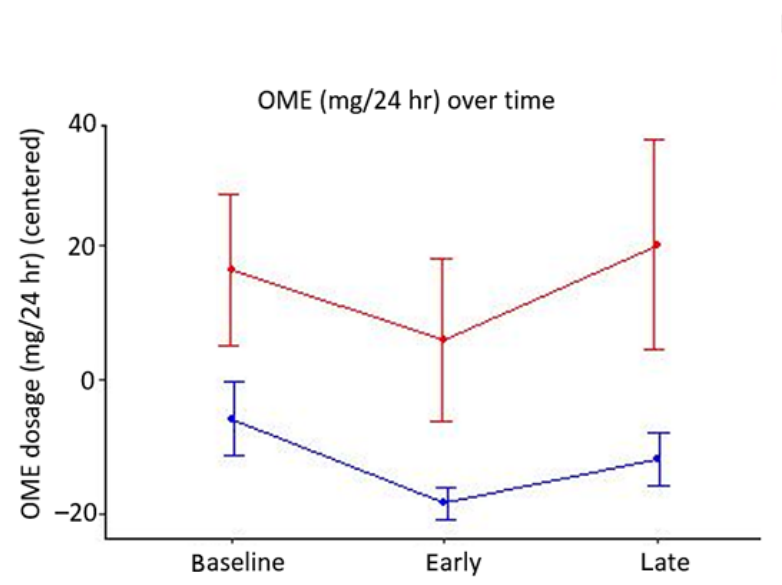

$$
\begin{aligned}
& \text { Intervention } \\
& \rightarrow \text { No } \\
& \rightarrow \text { Yes }
\end{aligned}
$$
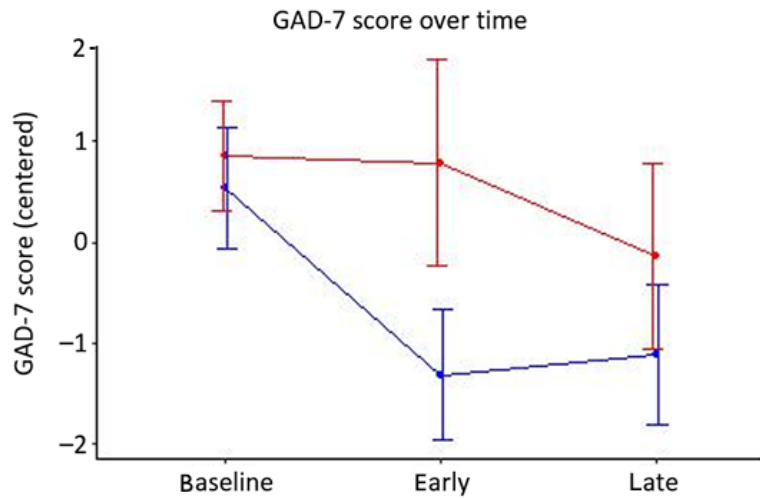

PDI score over time

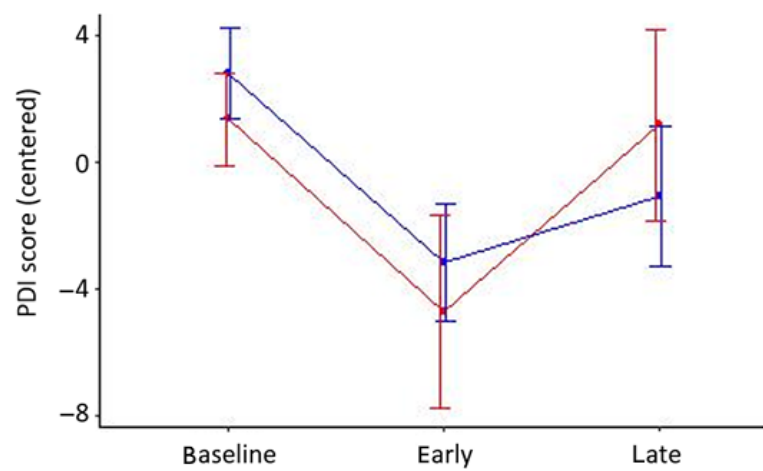

PGIC (percentage of participants improved)

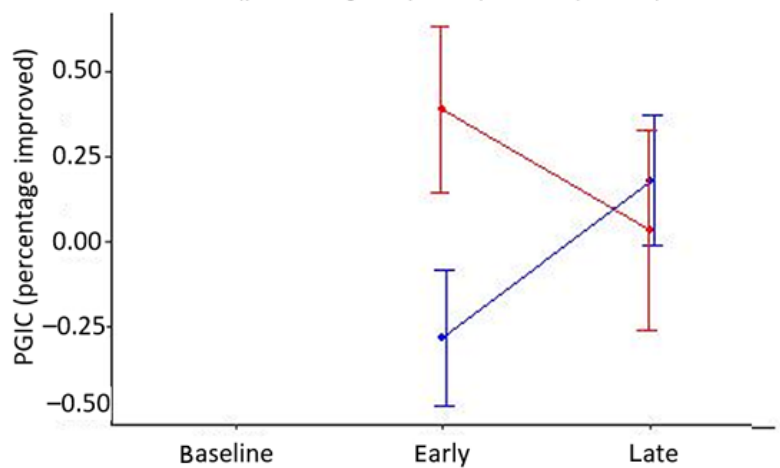

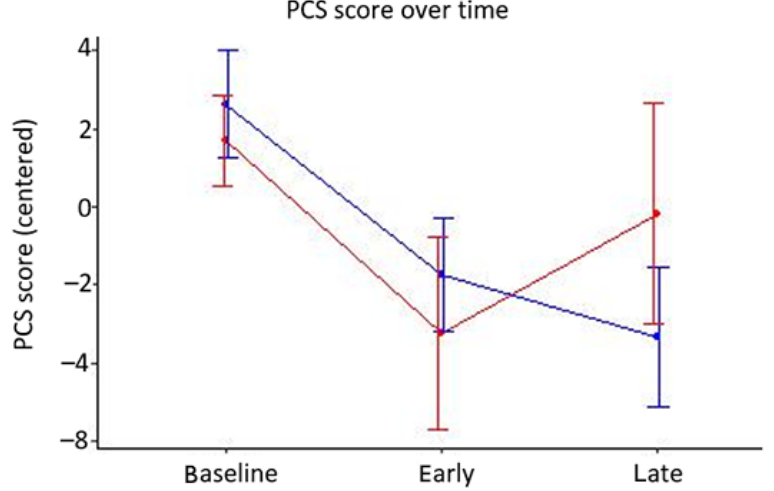


Table 4. Unadjusted outcomes stratified by time and group. The differences between the intervention and control groups are represented as absolute numbers with their 95\% CIs, and 95\% CI for OME used bootstrapped values.

\begin{tabular}{|c|c|c|c|c|}
\hline Time & App group & Nonapp group & Difference $(95 \% \mathrm{CI})$ & $P$ value \\
\hline \multicolumn{5}{|c|}{$\mathrm{OME}^{\mathrm{a}}(\mathrm{mg} / 24 \mathrm{hr})$, median (IQR) } \\
\hline Baseline & $0(0-27)$ & $0(0-30)$ & $0(-14$ to 0$)$ & .39 \\
\hline Short-term & $0(0-15)$ & $0(0-27)$ & $0(-30$ to 0$)$ & .18 \\
\hline Long-term & $0(0-23)$ & $2(0-73)$ & $-2(-71$ to 0$)$ & .16 \\
\hline \multicolumn{5}{|l|}{ GAD-7 ${ }^{b}$ score, mean (SD) } \\
\hline Baseline & $8.21(6.35)$ & $8.53(6.23)$ & $-0.32(-1.95$ to 1.30$)$ & .70 \\
\hline Short-term & $6.34(6.17)$ & $8.46(6.13)$ & $-2.12(-4.58$ to 0.35$)$ & .09 \\
\hline Long-term & $6.54(5.86)$ & $7.53(5.14)$ & $-0.99(-3.34$ to 1.36$)$ & .43 \\
\hline \multicolumn{5}{|l|}{ PHQ-9 ${ }^{\mathbf{c}}$ score, mean (SD) } \\
\hline Baseline & $11.52(6.66)$ & $11.35(6.78)$ & $0.17(-1.57$ to 1.91$)$ & .85 \\
\hline Short-term & $8.66(6.93)$ & $9.63(5.92)$ & $-0.97(-3.46$ to 1.53$)$ & .47 \\
\hline Long-term & $9.03(5.88)$ & $9.17(6.84)$ & $-0.14(-3.02$ to 2.75$)$ & .92 \\
\hline \multicolumn{5}{|l|}{ PDI $^{d}$ score, mean (SD) } \\
\hline Baseline & $41.76(15.11)$ & $40.32(16.53)$ & $1.44(-2.67$ to 5.55$)$ & .49 \\
\hline Short-term & $35.78(17.57)$ & $34.23(18.37)$ & $1.55(-5.74$ to 8.83$)$ & .67 \\
\hline Long-term & $37.90(18.32)$ & $40.14(16.74)$ & -2.24 ( -10.01 to 5.52$)$ & .58 \\
\hline \multicolumn{5}{|l|}{ PCS $^{\mathrm{e}}$ score, mean (SD) } \\
\hline Baseline & $24.93(14.39)$ & $24.00(13.13)$ & $0.93(-2.65$ to 4.51$)$ & .61 \\
\hline Short-term & $20.58(13.77)$ & $19.06(14.84)$ & $1.52(-4.32$ to 7.36$)$ & .59 \\
\hline Long-term & $18.97(14.94)$ & $22.13(15.80)$ & $-3.16(-10.00$ to 3.67$)$ & .35 \\
\hline \multicolumn{5}{|l|}{ PGIC $^{\text {f }}$ score $^{\mathrm{g}}, \mathrm{n} / \mathrm{N}(\%)$} \\
\hline Baseline & $\mathrm{N} / \mathrm{A}^{\mathrm{h}}$ & N/A & N/A & N/A \\
\hline Short-term (improved) & $32 / 89(36.0)$ & $15 / 32(46.9)$ & $-10.9 \%(-33.0 \%$ to $11.1 \%)$ & .38 \\
\hline Long-term (improved) & $24 / 58(41.4)$ & $11 / 28(39.3)$ & $2.1 \%(-22.1 \%$ to $26.3 \%)$ & $>.99$ \\
\hline
\end{tabular}

aOME: oral morphine equivalents.

${ }^{\mathrm{b}}$ GAD-7: Generalized Anxiety Disorder 7-item scale.

${ }^{\mathrm{c}}$ PHQ-9: Patient Health Questionnaire 9-item scale.

${ }^{\mathrm{d}}$ PDI: Pain Disability Index.

${ }^{\mathrm{e}} \mathrm{PCS}$ : Pain Catastrophizing Scale.

${ }^{f}$ PGIC: Patient Global Impression of Change.

${ }^{\mathrm{g}}$ PGIC score represents participants who improved.

${ }^{\mathrm{h}} \mathrm{N} / \mathrm{A}$ : not applicable.

\section{Adjusted Analysis for the Entire Study Cohort}

A significant decline in daily OME in milligrams was observed in both the short-term (decrease of $8.31 \mathrm{mg}, 95 \% \mathrm{CI}-16.62$ to -0.97 ) and long-term (decrease of 12.59 points, $95 \%$ CI -21.16 to 4.27) time periods when compared with baseline. Depression (PHQ-9) (lower by 2.29 points, $95 \% \mathrm{CI}-3.23$ to -1.34 in the short-term follow-up; lower by 2.52 points, $95 \% \mathrm{CI}-3.56$ to -1.47 in the long-term follow-up) and disability (PDI) scores (lower by 5.20 points, $95 \% \mathrm{CI}-7.60$ to -2.81 in the short-term follow-up; lower by 3.52 points, $95 \% \mathrm{CI}-6.20$ to -0.80 in the long-term follow-up) decreased significantly for all participants
(Multimedia Appendix 1). Pain Catastrophizing Scale scores decreased at the short-term follow-up, with the scores lowered by 3.53 points $(95 \% \mathrm{CI}-6.88$ to -0.17 ) but returned to baseline at the long-ter $\mathrm{m}$ follow-up. Older participants reported lower opioid use over time, with a decrease of $0.98 \mathrm{mg}$ of OME per year of increasing age ( $95 \% \mathrm{CI}-1.80$ to -0.08$)$. Increasing age was also associated with lower GAD-7, PHQ-9, PDI, and PCS scores (Multimedia Appendix 1). Male sex was associated with a higher disability score throughout the study (Multimedia Appendix 1). 
Participants in the app group had lower anxiety (GAD-7) scores at the short-term follow-up (decrease of 2.10 points, 95\% CI -3.96 to -0.24 ) and lower Pain Catastrophizing Scale scores at the long-term follow-up (decrease of 5.23 points, $95 \% \mathrm{CI}-9.55$ to -0.91) (Multimedia Appendix 1). For the reduction in the anxiety and pain catastrophizing scores, there was a significant intervention-by-time interaction, indicating that the decrease in these scores was higher in the group that used the app. There was also a change over time for the daily OME (lower by 12.59 $\mathrm{mg}, 95 \%$ CI -21.16 to -4.27 ), PHQ-9 score (decrease of 2.52 points, $95 \% \mathrm{CI}-3.56$ to -1.47 ), and PDI score (decrease of 3.52 points, $95 \%$ CI -6.20 to -0.80 ), but there was no time-by-intervention interaction, indicating that the change in outcome over time was not different between those who used the app and those who did not.

\section{Discussion}

\section{Summary of the Main Results of the Study}

This is the first multisite study at rural and urban pain clinics of a digital pain management solution that compared outcomes in patients with chronic pain who chose to use the app in addition to standard care versus those who received only standard care. A total of $73.6 \%(181 / 246)$ of the participants in the study chose to enroll for the app, $45.1 \%$ (111/246) continued to use it beyond one month following enrollment, and $28.0 \%$ (69/246) were still using it for 4.5 to 7 months. There was evidence of a decrease in anxiety and pain catastrophizing in participants who used the app versus those who did not use the app.

\section{Acceptance of and Engagement With the App}

Digital health applications can play a significant role in enhancing the connectivity between patients and their HCPs. Though some studies report men and younger age groups as more likely to engage with this kind of technology [45], our study and others did not find differences based on age and sex $[45,46]$. It is possible that the chronicity of pain in participants in our study and the lack of effective therapies made patients in our study interested in exploring the potential for help from the app offered in our study. The rates of initial engagement with the app reported in our study-initially $73.6 \%$ (181/246), with a gradual decrease to $28.0 \%(69 / 246)$ at the long-term follow-up - are consistent with those reported in literature by our group [47] and others [45,48,49] and appear to be better than the rates for other apps [24]. We measured ongoing engagement with the digital app, unlike other studies that evaluate merely the intent of patients to engage with digital health solutions [46]. Continuing engagement with digital health solutions is important, and international health organizations have also emphasized the importance of developing evidence for the integration of digital health solutions in routine medical care $[27,28]$ because of their potential to empower and enable patients. A follow-up study will focus on the engagement patterns and their contributing factors within this study along with their potential correlations with the clinical outcomes seen.

\section{Association of Using the App With Pain-Related Clinical Outcomes}

Our study found that use of the app was associated with a reduction in pain-related anxiety and pain catastrophizing scores. These reductions have clinical significance, given that the minimum clinically important difference in values for the GAD-7 and PCS (-4 for GAD-7 [50] and 38\% for PCS [51]) is within the $95 \%$ confidence interval of the outcome reduction. Pain-related anxiety and catastrophizing can have significant adverse effects on patients, with an increase in both health care use [52] and the probability of misuse of prescription opioids [53].

The ability of patients to track and reflect on their pain and its relationship to activities and medications in our study may have resulted in an attenuation of the psychological correlates of chronic pain. Self-monitoring of symptoms is an important component of most pain self-management programs [54]. There is a growing body of evidence that self-monitoring using eHealth tools is associated with positive health outcomes [55]. In particular, the daily reflection concept used by Manage My Pain is a form of self-monitoring based on acceptance and commitment therapy principles, which is an empirically supported treatment for individuals living with chronic pain [56]. It emphasizes engagement in meaningful activities based on personal values as a cornerstone of treatment [57]. The use of the app's diary of patients' lived experiences when interacting with HCPs through reports or the remote monitoring portal possibly empowered patients to address their negative emotions. This empowerment has been known to be associated with an analgesic benefit over time in patients with chronic pain [58,59]. Studies on other chronic health conditions have also reported similar results [60]. While the differences in the other clinical domains between the intervention and control groups were not significant, it is possible that these differences would be significant if the sample size were larger. Further, we did not include pain intensity scores in our study because this instrument has been shown to lack the ability to demonstrate functional benefits of analgesic interventions [61].

This study suggests that engagement by patients with an app-based digital pain solution that incorporates validated questionnaires may be associated with improvement in clinical outcomes. A future study will present the results of a qualitative analysis that assessed both the patients' and clinical team's perspective on the app's utility. Additionally, further research is required to understand factors that impact initial acceptance and continuing engagement with digital apps in patients with pain, including user comfort, understanding of technology, accessibility for patients and connectivity with HCPs, and feasibility of implementation in established health care systems [62].

\section{Limitations of This Study}

This study of the outcomes of the use of an app-based digital solution for generalized chronic pain has some limitations. Participants in this study were not allocated to study groups by randomization. This could have introduced a bias because patients comfortable with digital technology were more likely to opt to use the app. An additional bias could have been 
introduced in that patients who chose to use the app would have seen clinical improvements regardless of app usage. The high drop-off rate from baseline to the short-term follow-up with the control group may have also introduced a bias in the results. However, the fact that that a large number of patients in this control group were deemed not to qualify for treatments offered at the clinics and were therefore discharged implies that they would not have benefited relative to those at least receiving the standard of care. This may have also contributed to a higher dropout rate for using the app. All measures were based on participant self-reports, which were not verified by objective means (eg, clinical interview to assess anxiety and depressive disorders, verification of opioid use by pharmacy records). This may have resulted in biased estimates of results that differed by treatment group, confounding the present findings.

\section{Conclusions}

This study of a novel digital pain management solution that incorporated validated measures for domains of pain in patients at urban and rural clinics found that $28.0 \%(69 / 246)$ of all patients continued to use the app on a long-term basis. Patients that engaged with the digital health solution had less anxiety and lower pain catastrophizing scores as measured by validated tools. Digital pain management applications and other health-related clinical applications deserve significant attention in the years ahead, given the push toward mobile health tools and telemedicine.

\section{Acknowledgments}

The authors would like to acknowledge the support from the Department of Anesthesia and Pain Medicine at the University Health Network, Toronto, Ontario, Canada. The authors would also like to thank Dr Stephen Chiang and Dr Auri Bruno-Petrina of the Iroquois Falls Family Health Team.

\section{Conflicts of Interest}

TJ is the founder and CEO of ManagingLife Inc, the owner of Manage My Pain. The other authors declare no competing interests or conflicts of interest.

\section{Multimedia Appendix 1}

Results of the adjusted analysis.

[DOCX File, 18 KB-Multimedia Appendix 1]

\section{References}

1. Schopflocher D, Taenzer P, Jovey R. The prevalence of chronic pain in Canada. Pain Res Manag 2011;16(6):445-450 [FREE Full text] [doi: 10.1155/2011/876306] [Medline: 22184555]

2. Reitsma M, Tranmer J, Buchanan D, Vandenkerkhof E. The prevalence of chronic pain and pain-related interference in the Canadian population from 1994 to 2008. Chronic Dis Inj Can 2011 Sep;31(4):157-164. [doi: 10.24095/hpcdp.31.4.04]

3. Steingrímsdóttir Ó, Landmark T, Macfarlane GJ, Nielsen CS. Defining chronic pain in epidemiological studies: a systematic review and meta-analysis. Pain 2017 Nov;158(11):2092-2107. [doi: 10.1097/j.pain.0000000000001009] [Medline: 28767506]

4. Jackson T, Thomas S, Stabile V, Shotwell M, Han X, McQueen K. A Systematic Review and Meta-Analysis of the Global Burden of Chronic Pain Without Clear Etiology in Low- and Middle-Income Countries: Trends in Heterogeneous Data and a Proposal for New Assessment Methods. Anesth Analg 2016 Sep;123(3):739-748. [doi: 10.1213/ANE.0000000000001389] [Medline: 27537761]

5. Dahlhamer J, Lucas J, Zelaya C, Nahin R, Mackey S, DeBar L, et al. Prevalence of Chronic Pain and High-Impact Chronic Pain Among Adults - United States, 2016. Morb Mortal Weekly Rep 2018 Sep 14;67(36):1001-1006 [FREE Full text] [doi: 10.15585/mmwr.mm6736a2] [Medline: 30212442]

6. Hogan M, Taddio A, Katz J, Shah V, Krahn M. Incremental health care costs for chronic pain in Ontario, Canada: a population-based matched cohort study of adolescents and adults using administrative data. Pain 2016 Aug;157(8):1626-1633. [doi: 10.1097/j.pain.0000000000000561] [Medline: 26989805]

7. St Sauver JL, Warner DO, Yawn BP, Jacobson DJ, McGree ME, Pankratz JJ, et al. Why patients visit their doctors: assessing the most prevalent conditions in a defined American population. Mayo Clin Proc 2013 Jan;88(1):56-67 [FREE Full text] [doi: 10.1016/j.mayocp.2012.08.020] [Medline: 23274019]

8. Finley CR, Chan DS, Garrison S, Korownyk C, Kolber MR, Campbell S, et al. What are the most common conditions in primary care? Systematic review. Can Fam Physician 2018 Nov;64(11):832-840 [FREE Full text] [Medline: 30429181]

9. Wilson MG, Lavis JN, Ellen ME. Supporting chronic pain management across provincial and territorial health systems in Canada: Findings from two stakeholder dialogues. Pain Res Manag 2015;20(5):269-279 [FREE Full text] [doi: 10.1155/2015/918976] [Medline: 26291124]

10. Lynch ME. The need for a Canadian pain strategy. Pain Res Manag 2011;16(2):77-80 [FREE Full text] [doi: 10.1155/2011/654651] [Medline: 21499581]

11. Gaskin DJ, Richard P. The economic costs of pain in the United States. J Pain 2012 Aug;13(8):715-724. [doi: 10.1016/j.jpain.2012.03.009] [Medline: 22607834] 
12. Zhao P, Yoo I, Lancey R, Varghese E. Mobile applications for pain management: an app analysis for clinical usage. BMC Med Inform Decis Mak 2019 May 30;19(1):106 [FREE Full text] [doi: 10.1186/s12911-019-0827-7] [Medline: 31146739]

13. Kapoor A, Guha S, Kanti Das M, Goswami KC, Yadav R. Digital healthcare: The only solution for better healthcare during COVID-19 pandemic? Indian Heart J 2020;72(2):61-64 [FREE Full text] [doi: 10.1016/j.ihj.2020.04.001] [Medline: 32534691]

14. Eccleston C, Blyth FM, Dear BF, Fisher EA, Keefe FJ, Lynch ME, et al. Managing patients with chronic pain during the COVID-19 outbreak: considerations for the rapid introduction of remotely supported (eHealth) pain management services. Pain 2020 May;161(5):889-893 [FREE Full text] [doi: 10.1097/j.pain.0000000000001885] [Medline: $\underline{32251203]}$

15. Portelli P, Eldred C. A quality review of smartphone applications for the management of pain. Br J Pain 2016 Aug;10(3):135-140 [FREE Full text] [doi: 10.1177/2049463716638700] [Medline: 27583140]

16. Alexander JC, Joshi GP. Smartphone applications for chronic pain management: a critical appraisal. J Pain Res 2016;9:731-734 [FREE Full text] [doi: 10.2147/JPR.S119966] [Medline: 27713649]

17. Salazar A, de Sola H, Failde I, Moral-Munoz JA. Measuring the Quality of Mobile Apps for the Management of Pain: Systematic Search and Evaluation Using the Mobile App Rating Scale. JMIR Mhealth Uhealth 2018 Oct 25;6(10):e10718 [FREE Full text] [doi: 10.2196/10718] [Medline: $\underline{\text { 30361196] }}$

18. Bedson J, Hill J, White D, Chen Y, Wathall S, Dent S, et al. Development and validation of a pain monitoring app for patients with musculoskeletal conditions (The Keele pain recorder feasibility study). BMC Med Inform Decis Mak 2019 Jan 25;19(1):24 [FREE Full text] [doi: 10.1186/s12911-019-0741-z] [Medline: $\underline{\text { 30683106] }}$

19. Jamison RN, Mei A, Ross EL. Longitudinal trial of a smartphone pain application for chronic pain patients: Predictors of compliance and satisfaction. J Telemed Telecare 2016 Nov 10;24(2):93-100. [doi: 10.1177/1357633x16679049]

20. Ross EL, Jamison RN, Nicholls L, Perry BM, Nolen KD. Clinical Integration of a Smartphone App for Patients With Chronic Pain: Retrospective Analysis of Predictors of Benefits and Patient Engagement Between Clinic Visits. J Med Internet Res 2020 Apr 16;22(4):e16939 [FREE Full text] [doi: 10.2196/16939] [Medline: 32297871]

21. Jamison RN, Jurcik DC, Edwards RR, Huang C, Ross EL. A Pilot Comparison of a Smartphone App With or Without 2-Way Messaging Among Chronic Pain Patients: Who Benefits From a Pain App? Clin J Pain 2017 Aug;33(8):676-686 [FREE Full text] [doi: 10.1097/AJP.0000000000000455] [Medline: 27898460]

22. Priebe JA, Haas KK, Moreno Sanchez LF, Schoefmann K, Utpadel-Fischler DA, Stockert P, et al. Digital Treatment of Back Pain versus Standard of Care: The Cluster-Randomized Controlled Trial, Rise-uP. J Pain Res 2020 Jul;13:1823-1838. [doi: 10.2147/jpr.s260761]

23. Roberts A, Philip L, Currie M, Mort A. Striking a balance between in-person care and the use of eHealth to support the older rural population with chronic pain. Int J Qual Stud Health Well-being 2015;10:27536 [FREE Full text] [doi: 10.3402/qhw.v10.27536] [Medline: 26336996]

24. Adjust Global App Trends 2019: Global Benchmark Reports. Adjust. 2019. URL: https://www.adjust.com/resources/ebooks/ adjust-global-app-trends-report-2019/ [accessed 2021-02-19]

25. ManagingLife. ManagingLife Inc. URL: https://managinglife.com/ [accessed 2020-01-15]

26. Manage My Pain: Track, analyze, and monitor your pain. ManagingLife Inc. URL: https://managemypainapp.com/ [accessed 2021-02-20]

27. Weinrib A, Azam MA, Latman VV, Janmohamed T, Clarke H, Katz J. Manage my pain: A patient-driven mobile platform to prevent and manage chronic postsurgical pain. In: Chronic Illness and Long-Term Care: Breakthroughs in Research and Practice. Hershey, PA: IGI Global; 2018:642-667.

28. Rahman QA, Janmohamed T, Pirbaglou M, Clarke H, Ritvo P, Heffernan JM, et al. Defining and Predicting Pain Volatility in Users of the Manage My Pain App: Analysis Using Data Mining and Machine Learning Methods. J Med Internet Res 2018 Nov 15;20(11):e12001 [FREE Full text] [doi: 10.2196/12001] [Medline: 30442636]

29. Rahman QA, Janmohamed T, Clarke H, Ritvo P, Heffernan J, Katz J. Interpretability and Class Imbalance in Prediction Models for Pain Volatility in Manage My Pain App Users: Analysis Using Feature Selection and Majority Voting Methods. JMIR Med Inform 2019 Nov 20;7(4):e15601 [FREE Full text] [doi: 10.2196/15601] [Medline: 31746764]

30. Rahman QA, Janmohamed T, Pirbaglou M, Ritvo P, Heffernan JM, Clarke H, et al. Patterns of User Engagement With the Mobile App, Manage My Pain: Results of a Data Mining Investigation. JMIR Mhealth Uhealth 2017 Jul 12;5(7):e96 [FREE Full text] [doi: 10.2196/mhealth.7871] [Medline: 28701291]

31. Palinkas LA, Horwitz SM, Green CA, Wisdom JP, Duan N, Hoagwood K. Purposeful Sampling for Qualitative Data Collection and Analysis in Mixed Method Implementation Research. Adm Policy Ment Health 2015 Sep;42(5):533-544 [FREE Full text] [doi: 10.1007/s10488-013-0528-y] [Medline: 24193818]

32. Woo AK. Depression and Anxiety in Pain. Rev Pain 2010 Mar;4(1):8-12 [FREE Full text] [doi: 10.1177/204946371000400103] [Medline: 26527193]

33. Sheng J, Liu S, Wang Y, Cui R, Zhang X. The Link between Depression and Chronic Pain: Neural Mechanisms in the Brain. Neural Plast 2017;2017:9724371 [FREE Full text] [doi: 10.1155/2017/9724371] [Medline: 28706741]

34. Kroenke K, Wu J, Yu Z, Bair MJ, Kean J, Stump T, et al. Patient Health Questionnaire Anxiety and Depression Scale. Psychosom Med 2016;78(6):716-727. [doi: 10.1097/psy.0000000000000322] 
35. Kroenke K, Yu Z, Wu J, Kean J, Monahan PO. Operating characteristics of PROMIS four-item depression and anxiety scales in primary care patients with chronic pain. Pain Med 2014 Nov;15(11):1892-1901 [FREE Full text] [doi: 10.1111/pme.12537] [Medline: 25138978]

36. Zhong Q, Gelaye B, Zaslavsky AM, Fann JR, Rondon MB, Sánchez SE, et al. Diagnostic Validity of the Generalized Anxiety Disorder - 7 (GAD-7) among Pregnant Women. PLoS One 2015;10(4):e0125096 [FREE Full text] [doi: 10.1371/journal.pone.0125096] [Medline: 25915929]

37. Seo J, Park S. Validation of the Generalized Anxiety Disorder-7 (GAD-7) and GAD-2 in patients with migraine. J Headache Pain 2015;16:97 [FREE Full text] [doi: 10.1186/s10194-015-0583-8] [Medline: 26596588]

38. Rayner L, Hotopf M, Petkova H, Matcham F, Simpson A, McCracken LM. Depression in patients with chronic pain attending a specialised pain treatment centre: prevalence and impact on health care costs. Pain 2016 Jul;157(7):1472-1479 [FREE Full text] [doi: 10.1097/j.pain.0000000000000542] [Medline: 26963849]

39. Beemster T, van Bennekom C, van Velzen J, Reneman M, Frings-Dresen M. The interpretation of change score of the pain disability index after vocational rehabilitation is baseline dependent. Health Qual Life Outcomes 2018 Sep 14;16(1):182 [FREE Full text] [doi: 10.1186/s12955-018-1000-1] [Medline: 30217206]

40. Quartana PJ, Campbell CM, Edwards RR. Pain catastrophizing: a critical review. Expert Rev Neurother 2009 May;9(5):745-758 [FREE Full text] [doi: 10.1586/ern.09.34] [Medline: 19402782]

41. Sullivan MJL, Thorn B, Rodgers W, Ward LC. Path model of psychological antecedents to pain experience: experimental and clinical findings. Clin J Pain 2004;20(3):164-173. [doi: 10.1097/00002508-200405000-00006] [Medline: 15100592]

42. Perrot S, Lantéri-Minet M. Patients' Global Impression of Change in the management of peripheral neuropathic pain: Clinical relevance and correlations in daily practice. Eur J Pain 2019 Jul;23(6):1117-1128. [doi: 10.1002/ejp.1378] [Medline: 30793414]

43. Kahan M, Mailis-Gagnon A, Tunks E. Canadian guideline for safe and effective use of opioids for chronic non-cancer pain: implications for pain physicians. Pain Res Manag 2011;16(3):157-158 [FREE Full text] [doi: 10.1155/2011/434298] [Medline: 21766064]

44. Fitzmaurice G, Laird N, Ware J. Applied longitudinal Analysis. 2nd ed. Hoboken, NJ: Wiley; 2011.

45. Safi S, Danzer G, Schmailzl KJ. Empirical Research on Acceptance of Digital Technologies in Medicine Among Patients and Healthy Users: Questionnaire Study. JMIR Hum Factors 2019 Nov 29;6(4):e13472 [FREE Full text] [doi: 10.2196/13472] [Medline: 31782741]

46. Greis C, Meier Zürcher C, Djamei V, Moser A, Lautenschlager S, Navarini AA. Unmet digital health service needs in dermatology patients. J Dermatolog Treat 2018 Nov;29(7):643-647. [doi: 10.1080/09546634.2018.1441488] [Medline: 29455570]

47. Slepian PM, Peng M, Janmohamed T, Kotteeswaran Y, Manoo V, Blades AM, et al. Engagement with Manage My Pain mobile health application among patients at the Transitional Pain Service. Digit Health 2020;6:2055207620962297 [FREE Full text] [doi: 10.1177/2055207620962297] [Medline: 33117557]

48. Pratap A, Neto EC, Snyder P, Stepnowsky C, Elhadad N, Grant D, et al. Indicators of retention in remote digital health studies: a cross-study evaluation of 100,000 participants. NPJ Digit Med 2020;3:21 [FREE Full text] [doi: 10.1038/s41746-020-0224-8] [Medline: 32128451]

49. Eysenbach G. The law of attrition. J Med Internet Res 2005 Mar 31;7(1):e11 [FREE Full text] [doi: 10.2196/jmir.7.1.e11] [Medline: 15829473 ]

50. Toussaint A, Hüsing P, Gumz A, Wingenfeld K, Härter M, Schramm E, et al. Sensitivity to change and minimal clinically important difference of the 7-item Generalized Anxiety Disorder Questionnaire (GAD-7). J Affect Disord 2020 Mar 15;265:395-401. [doi: 10.1016/j.jad.2020.01.032] [Medline: 32090765]

51. Sullivan MJL, Bishop SR, Pivik J. The Pain Catastrophizing Scale: Development and validation. Psychol Assess 1995;7(4):524-532. [doi: 10.1037/1040-3590.7.4.524]

52. Lentz TA, Rhon DI, George SZ. Predicting Opioid Use, Increased Health Care Utilization and High Costs for Musculoskeletal Pain: What Factors Mediate Pain Intensity and Disability? J Pain 2020;21(1-2):135-145 [FREE Full text] [doi: 10.1016/j.jpain.2019.06.004] [Medline: $\underline{\text { 31201989] }}$

53. Martel MO, Wasan AD, Jamison RN, Edwards RR. Catastrophic thinking and increased risk for prescription opioid misuse in patients with chronic pain. Drug Alcohol Depend 2013 Sep 01;132(1-2):335-341 [FREE Full text] [doi: 10.1016/j.drugalcdep.2013.02.034] [Medline: 23618767]

54. Devan H, Hale L, Hempel D, Saipe B, Perry M. What Works and Does Not Work in a Self-Management Intervention for People With Chronic Pain? Qualitative Systematic Review and Meta-Synthesis. Phys Ther 2018 May 01;98(5):381-397. [doi: 10.1093/ptj/pzy029] [Medline: 29669089]

55. Lancaster K, Abuzour A, Khaira M, Mathers A, Chan A, Bui V, et al. The Use and Effects of Electronic Health Tools for Patient Self-Monitoring and Reporting of Outcomes Following Medication Use: Systematic Review. J Med Internet Res 2018 Dec 18;20(12):e294 [FREE Full text] [doi: 10.2196/jmir.9284] [Medline: $\underline{\text { 30563822] }}$

56. American Psychological Association. Acceptance and Commitment Therapy EST Status for Chronic or Persistent Pain: strong research support. Society of Clinical Psychology (Division 12). 2013. URL: http://www.div12.org/ 
psychological-treatments/disorders/chronic-or-persistent-pain/acceptance-and-commitment-therapy-for-chronic-pain/ [accessed 2015-06-01]

57. Polk KL, Schoendorff B, Webster M, Olaz FO. The Essential Guide to the ACT Matrix: A Step-by-Step Approach to Using the ACT Matrix Model in Clinical Practice. Oakland, CA: New Harbinger Publications; 2016.

58. Andias R, Neto M, Silva AG. The effects of pain neuroscience education and exercise on pain, muscle endurance, catastrophizing and anxiety in adolescents with chronic idiopathic neck pain: a school-based pilot, randomized and controlled study. Physiother Theory Pract 2018 Sep;34(9):682-691. [doi: 10.1080/09593985.2018.1423590] [Medline: 29319386]

59. Oerlemans S, van Cranenburgh O, Herremans P, Spreeuwenberg P, van Dulmen S. Intervening on cognitions and behavior in irritable bowel syndrome: A feasibility trial using PDAs. J Psychosom Res 2011 Mar;70(3):267-277. [doi: 10.1016/j.jpsychores.2010.09.018] [Medline: 21334498]

60. Torbjørnsen A, Ribu L, Rønnevig M, Grøttland A, Helseth S. Users' acceptability of a mobile application for persons with type 2 diabetes: a qualitative study. BMC Health Serv Res 2019 Sep 06;19(1):641 [FREE Full text] [doi:

10.1186/s12913-019-4486-2] [Medline: 31492176]

61. Pilitsis JG, Fahey M, Custozzo A, Chakravarthy K, Capobianco R. Composite Score Is a Better Reflection of Patient Response to Chronic Pain Therapy Compared With Pain Intensity Alone. Neuromodulation 2021 Jan;24(1):68-75. [doi: 10.1111/ner.13212] [Medline: 32592618]

62. Jandoo T. WHO guidance for digital health: What it means for researchers. Digit Health 2020;6:2055207619898984 [FREE Full text] [doi: 10.1177/2055207619898984] [Medline: $\underline{31949918]}$

\author{
Abbreviations \\ GAD-7: Generalized Anxiety Disorder 7-item scale \\ HCP: health care provider \\ IFFHT: Iroquois Falls Family Health Team \\ MMP: Manage My Pain \\ OME: oral morphine equivalents \\ PCS: Pain Catastrophizing Scale \\ PDI: Pain Disability Index \\ PGIC: Patient Global Impression of Change \\ PHQ-9: Patient Health Questionnaire 9-item scale \\ TGH: Toronto General Hospital \\ TWH: Toronto Western Hospital
}

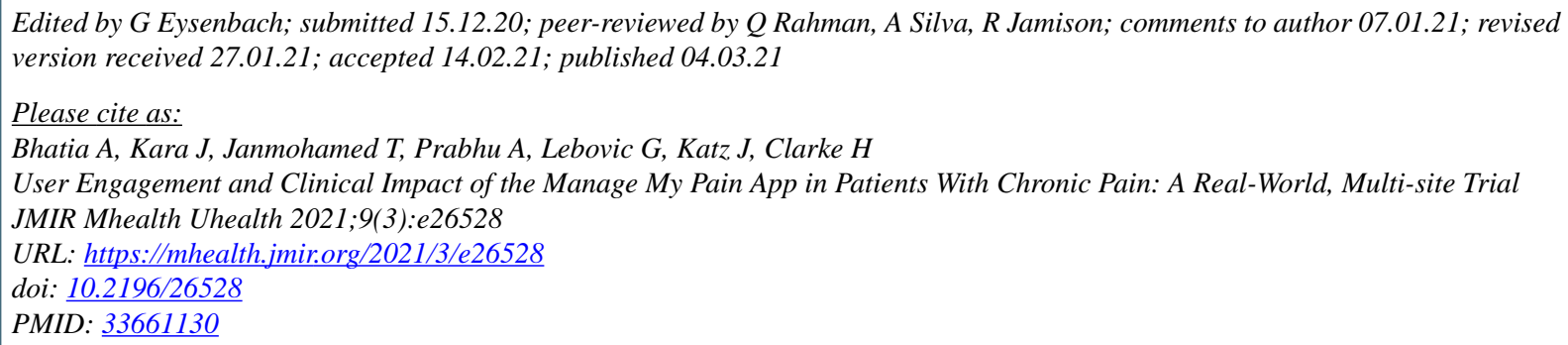

(C)Anuj Bhatia, Jamal Kara, Tahir Janmohamed, Atul Prabhu, Gerald Lebovic, Joel Katz, Hance Clarke. Originally published in JMIR mHealth and uHealth (http://mhealth.jmir.org), 04.03.2021. This is an open-access article distributed under the terms of the Creative Commons Attribution License (https://creativecommons.org/licenses/by/4.0/), which permits unrestricted use, distribution, and reproduction in any medium, provided the original work, first published in JMIR mHealth and uHealth, is properly cited. The complete bibliographic information, a link to the original publication on http://mhealth.jmir.org/, as well as this copyright and license information must be included. 